\title{
A Pilot Study of an Intervention for Children Using Music Listening and Music Making to Explore Core Emotions and Support Wellbeing
}

\author{
Elizabeth Liddiard ${ }^{1,2}$, Dawn Rose ${ }^{1,3^{*}}$ \\ ${ }^{1}$ Department of Psychology and Sport Sciences, School of Life Sciences, University of Hertfordshire, Hatfield, UK \\ ${ }^{2}$ William Austin Junior School, Luton, UK \\ ${ }^{3}$ School of Music, Lucerne University of Applied Sciences and Arts, Lucerne, Switzerland \\ Email: *dawn.rose@hslu.ch
}

How to cite this paper: Liddiard, E., \& Rose, D. (2021). A Pilot Study of an Intervention for Children Using Music Listening and Music Making to Explore Core Emotions and Support Wellbeing. Open Journal of Social Sciences, 9, 329-364.

https://doi.org/10.4236/jss.2021.93022

Received: February 22, 2021

Accepted: March 23, 2021

Published: March 26, 2021

Copyright $\odot 2021$ by author(s) and Scientific Research Publishing Inc. This work is licensed under the Creative Commons Attribution International License (CC BY 4.0).

http://creativecommons.org/licenses/by/4.0/

\begin{abstract}
Objective: Music-making and music listening can be experienced as having a positive influence on subjective wellbeing. This mixed methods study reports the development and findings of a pilot music intervention for children to explore core emotions to support feelings of belonging, empathy and self-esteem as key components of wellbeing. Methods: Children (aged 7 - 9 years, $n=17$ intervention, $\mathrm{n}=15$ control) were offered a brief intervention using music to explore five core emotions during a six-week after-school session including joy, sadness, anger, fear and disgust. Quantitative pre/post measures included the primary measure of musical aptitude (PMMA, intervention) and a selfreport questionnaire for items operationalised as wellbeing (children and parents). Qualitative methods included brainstorming, audio recordings and storyboarding. Results: Analyses of parent report revealed a significant increase in perceived sense of belonging for their child over time, and a positive association between increased PMMA and belonging from the children suggested the intervention was partially successful. Qualitative data provided insight into how music intervention enabled the development of belonging. Conclusion: The importance of using mixed methods to evaluate the efficacy of brief intervention is identified, and recommendations are made for a revised program using music-making to explore core emotions in children to support wellbeing in schools.
\end{abstract}

\section{Keywords}

Music Intervention, Children, Wellbeing, Mixed Methods, Arts Education, Emotion, Pro-Social Behaviours, Shared Goals, Empathy, Sense of Belonging, Self-Esteem 


\section{Introduction}

The need to advocate for music in schools demonstrates the fragility of the arts in education agenda, which attempts in the very least to provide an enriched environment for children (Hennessy, 2018; Henley, 2011, 2016). The strain on school budgets inexorably results in cuts in arts programs which can often be considered as "non-essential" subjects (Thomas, Singh, \& Klopfenstein, 2015). This is despite evidence of a synergistic relationship between the physical and mental health of students and academic attainment at all levels (Bonell et al., 2014). Various arguments and avenues have been explored in an attempt to support arts in schools, including but not limited to the prospect of social advantage via the provision of cultural capital (Hallam, 2010; Macdonald, Kreutz, \& Mitchell, 2014), and the impact of musical learning on cognitive and motor skills (Costa-Giomi, 2004; Hyde et al., 2009; Foster \& Jenkins, 2017; Rose, Jones Bartoli, \& Heaton, 2019).

However, the present focus in music psychology has been directed to the link between music and emotions (Eerola, 2018). This area has been underexplored in terms of intervention studies promoting social competencies underpinning wellbeing in children (Maury \& Rickard, 2016). Therefore, inspired by the popular animated children's film "Inside Out", in which characters embody the core emotions of joy, sadness, fear, anger and disgust, this paper relays the development and pilot testing of a novel intervention using group music listening and music-making to explore these core emotions in order to support wellbeing for children in a school in an area with low socio-economic status.

Music listening and music-making appears to be something unique to humans who share and create this auditory art in part to transfer emotional intent and alter affective states (Trehub \& Hannon, 2006; Juslin, 2013; Koelsch, 2014). Music in itself has been described as "affective messaging" (Maury \& Rickard, 2016: p. 7), with group singing especially generating shared positive emotional experiences, increasing group cohesion and pro-social behaviours (Clift \& Hancox, 2001). From an evolutionary perspective, some scholars have suggested that one reason for the emotional resonance in particular of group singing, might be because emotional utterances (protomusic) were the forerunners of communication skills in terms of language development (Mithen, 2006; Patel, 2017). Whilst the way in which we experience music can be both abstract and ephemeral, the way we use language requires more specificity. Therefore, although terms associated with affective states have historically been used interchangeably, here the term emotion/ $s$ is considered to be an experience either elicited by, or a reaction to-and generally about-something, in comparison to moods which tend to last longer and be more diffuse (Ekkekakis, 2013).

Juslin (2013) theorised that humans have a "shared acoustic code" for expressing emotions within music and music has been shown to evoke or arouse emotions during at least half of listening experience experiments (Ball, 2010; Juslin \& Laukka, 2004). In naturalistic music, research has shown that people can generally distinguish between five basic emotions: happiness, sadness, anger, 
fear, and love (or tenderness) (Juslin \& Laukka, 2003). Children are able to label core emotions between the age of four and five years (Widen \& Russell, 2008), and by the age of six to eight years, they can discriminate between music that sounds happy, sad, and angry, or represents "fear" (Kastner \& Crowder, 1990).

Multiple mechanisms linking emotion in music to human behaviour have been suggested (for overviews see Koelsch, 2014; Juslin, Barradas, \& Eeerola, 2015). Here we focus on those aspects most pertinent to potential interventions for children in school settings. From the eight mechanisms outlined in the BRECVEMA framework (Juslin \& Västfjäll, 2008), three factors offer further insight into the potential value of using music to explore emotions to support wellbeing: evaluative conditioning, contagion and episodic memory. The first of these captures the relationship between repeated experiences and positive affect. School studies have shown that whilst poor academic attainment is associated with disengagement and anti-social behaviours, shared positive emotional experiences (such as those generated through co-creating music) can lead to feelings of belonging and have a protective effect on self-esteem (Choi, Lee, \& Lee, 2010; Maury \& Rickard, 2016; Clements-Cortés \& Chow, 2018).

This in turn is linked to the second factor, contagion, which refers to the shared meaning experienced through emotional expression via the many voices of music (Juslin, 2013). Emotional contagion can be experienced through listening to music (Groarke \& Hogan, 2016; Loersch \& Arbuckel, 2013). However, it is more actively embodied in group singing, studies of which have demonstrated increases in pro-social behaviours, social bonding and wellbeing (e.g., Clift et al., 2007; Fredickson \& Joiner, 2002), especially for marginalised groups (Cohen, 2007). Through the notion of emotional contagion, the effects of joint musical experiences have been linked to empathy in line with the development of theory-ofmind skills (Kirschner \& Tomasello, 2010; Rabinowitch, Cross, \& Burnard, 2013). The third BRECVEMA factor, episodic memory, suggest past experience may trigger affective responses. This is generally considered as positive, such as the sense of belonging engendered through the group singing of anthems. However, as a more positive effect for "outside" compared to "inside" school music experiences, the context must be carefully considered (Lamont et al., 2003).

The efficacy of music in terms of intervention studies for children's wellbeing in schools have been somewhat equivocal, in part due to differences in methodological approaches, measured outcomes and what has been described as the "wicked problem" of the term wellbeing (Rickard, Bambrick, \& Gill, 2012; Svane, Evans \& Carter, 2019). Overall, the main focus has either been on improving cognitive abilities, and therefore the future prospects of the children (e.g., Bugos, Perlstein, McCrae, Brophy, \& Bedenbaugh, 2007; Mehr et al., 2013; Moreno et al., 2011; Schäfer, Smukalla, \& Oelker, 2014), or reducing negative behaviours. For example, improving the ability to perceive emotions has been associated with reduced physical and verbal aggression in children aged seven-12 years who attended a 24-week music programme (Kim \& Kim, 2018). Similarly, Faulkner, 
Wood, Ivery and Donovan (2012) reported an association between a ten-week drumming intervention for thirty 12 -year-old boys and observations of reduced anti-social behaviours, improved self-esteem, better school attendance and more cooperative behaviour from the boys. However, other studies have failed to find psychosocial benefits (Rickard et al., 2013; Schellenberg, 2004).

Maury and Rickard (2016) advocate for an alternative approach focusing on the promotion of social competencies. This is based on evidence suggesting that cocreating and listening to music develops empathy and bonding through shared experiences (Ritchie \& Williamon, 2011). For example, Dingle and Fay (2013) found a significant increase in emotion regulation skills in young adults when compared to a control group following a four-week intervention of music listening and lyric analysis. Musical learning has also been shown to promote self-esteem, alongside developing empathy (Costa-Giomi, 2004; Hietolahti-Ansten \& Kalliopuska, 1990).

Furthermore, as musical skills are learned, performing and improvisation increase opportunities for social-interaction and team-work due to shared goals as has been noted in a number of studies also demonstrating increased self-esteem and pro-social behaviours (Clift, 2010; McPherson, Davidson, \& Faulkner, 2012; Swanson \& Campbell, 2016). This can be especially important in areas of low socio-economic status as demonstrated in a study by Zapata and Hargreaves (2017) who delivered an 18-week music programme to displaced children in Columbia, as well as for children with special educational needs (Geretsegger, Holck, Carpente, Elefant, Kim, \& Gold, 2015; Gilboa, Bodner \& Amir, 2006; Rose, Jones Bartoli, \& Heaton, 2018; Simpson \& Keen, 2011).

Overall, musical activities have been shown to have positive effects on both the hedonic (pleasure) and eudaemonic (meaning) aspects of wellbeing (Lamont, 2012; Zuo, Wang, Wang, \& Shi, 2017). However, wellbeing is often measured using self-report, and this method has been questioned when used with children under the age of nine (Zeman, Klimes-Dougan, Cassano, \& Adrian, 2007). Therefore, researchers have advised using multiple methods, including quantitative and qualitative approaches, to put children at the heart of the research and enable a deeper understanding of the impact of the intervention (Clarke, Sixsmith, \& Barry, 2014; Darbyshire, MacDougall, \& Schiller, 2005).

\section{Aims and Hypothesis}

The aim of this study was to investigate the impact of a novel six-week intervention that used music-listening and active music-making (via a weekly music club) to explore core emotions to support wellbeing in children (aged seven-nine years old) living in an area of low socio-economic status in the UK. Based on the literature review, wellbeing was operationalised as including empathy, sense of belonging and self-esteem. The hypotheses posited that children who chose to participate in the music programme would 1) have improved their musicality according to scores on the Primary Measures of Music Audiation (PMMA; Gordon, 1986), and 2) have improved their scores on a measure of wellbeing following the intervention compared to a control group of children who did not take part. 


\section{Methodology}

\subsection{Methods}

\subsubsection{Design}

This study was a mixed-methods between and within-subjects repeated measures design. The two conditions included an intervention group of children who participated in the weekly "music club", and a control group who did not. Quantitative measures included a non-validated Children's Wellbeing Questionnaire (CWQ, Appendix E) and a parent/caregiver version of the same questions (though the wording was adjusted) to reflect their observations on the children (PQ, Appendix F), and a validated tool assessing children's musical aptitude, the Primary Measures of Music Audiation (PMMA; Gordon, 1986). Qualitative data collection methods included a brainstorming activity (flip chart), observation (field notes from a research assistant), audio recordings and storyboards.

\subsubsection{Participants}

The children who took part in the study attended school in an area of low socio-economic status according to the ward profile (Central Bedfordshire Council, 2015). The music intervention was optional and was offered as a novel after-school "music club" to the children in years three and four in the school in which the first author worked at the time of the study. The new music club was described to the children in their weekly assemblies and letters were sent out the parents explaining about the club and the intention of the study outlining to aims of the intervention, and inviting participation.

A total of 42 children initially signed up for the study and 32 participated in the music club across the course of the study, though only $n=17$ completed the measures for the intervention and $n=15$ for the control group. See Table 1 for participant details.

Table 1. Participant information.

\begin{tabular}{ccc}
\hline Participant Description & Intervention Group & Control Group \\
\hline Year 3 (Age from 7 to 8 years, 6 months) & 7 & 6 \\
Year 4 (Age from 8 years, 7 months to 9 years) & 10 & 9 \\
Female & 12 & 7 \\
Male & 5 & 8 \\
Pupil Premium $^{\mathrm{a}}$ & 3 & 4 \\
Non-Pupil Premium & 14 & 11 \\
Special Educational Needs & \\
Non-Special Educational Needs & 3 & 1 \\
Total & 14 & 14 \\
Parent/Care-giver & 17 & 0
\end{tabular}

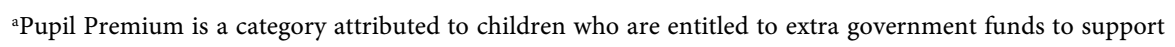
their learning whilst in school. bSpecial Educational Needs (SEN) is a category that referring to children with special educational needs as identified if the child has an Education Health Plan (EHP). The EHP outlines any specialist provision the child needs to allow them to access their learning fully within school. The three children who are considered SEN in the intervention group had been diagnosed with autistic spectrum disorder (ASD). 
Approval for the study was obtained from the ethics committee with delegated authority at the School of Life Sciences, University of Hertfordshire. The primary school agreed for the research to be undertaken on the school premises and also approved the study. Written consent was obtained from the participant's parents or caregivers. Before each session of the music club, the children were read a consent script (Appendix A) and at the end of the session a debrief script (Appendix B) to ensure they were fully informed of each session and gave their full verbal consent. The control group were also read a consent script (Appendix C).

\subsubsection{Procedure}

Children attended a music intervention group for a period of six weeks (see Appendix D for session plan) in the second half of the summer term in 2018. At the end of each session the children completed a non-validated measure, the Children's Wellbeing Questionnaire (CWQ) incorporating aspects of empathy, belonging and self-esteem (see Materials and Appendix E). Parents of the intervention group were asked to complete a separate non-validated measure, the Parents Questionnaire (PQ), at the start and at the end of the six-week period (see Appendix F). At the start and at the end of the intervention the children completed the Primary Measures of Music Aptitude (PMMA; Gordon, 1986). The control group completed the CWQ only (Appendix E) at the start and end of the six-week period.

\subsection{Materials}

\subsubsection{Intervention}

The intervention was written by the first author (see Session Plans, Appendix D), a primary school teacher who was completing an MSc in psychology. These ideas were developed to specifically focus on using music to explore core emotions inspired by the animated children's film, Inside Out (Docter \& Del Carmen, 2015) to support wellbeing, operationalised as including apsects of self-esteem, belonging and empathy. Each of the six sessions comprised of four components associated with music: listening, singing, improvisation and performing. These aspects were incorporated because music is a complex activity and it is difficult to distinguish which area is responsible for having an impact on wellbeing (Kamioka et al., 2014). In accordance with Juslin (2013), the core emotions of joy, sadness, anger, disgust and fear were explored. The final session gave the children the opportunity to create an emotion storyboard of their intervention experience.

To introduce the emotion of the week every session the children listened to examples of music representing those emotions (one song per emotion, see Appendix G). These songs were chosen by the teacher based on previous experience with other children in the school who had responded to the songs. This gave the children the opportunity to hear and discuss why they thought it did, or did not, represent the emotion of the week. Even though some of the emotions 
were perceived as negative, listening to music provoking these emotions has been found to produce a positive reaction. For example, Kawakami, Furukawa, Katahira and Okanoya (2013) found that when participants listened to music which sounded "tragic", the participants reported to have feelings of romance and happiness.

Singing was used as a way to open the sessions due to its collective nature (Mellor, 2013; Svec, 2018). The programme Sing Up (2019) is an online subscription music service funded by the school which was used to access many songs the children were familiar with from singing in their weekly assemblies and which were used during their day-to-day classroom lessons. At the start of each session, the children in the intervention group had a vote each week to determine which three songs they wanted to sing that week.

Improvisation has also been suggested as a skill which is accessible for all (Macdonald \& Wilson, 2014; McPherson, Davidson, \& Faulkner, 2012). Therefore, this aspect of music making was included so the children could explore their knowledge of the basic emotions with music. Within the sample there were three children diagnosed with autism spectrum disorder (ASD), and improvisation has been found to improve interactive behaviour for children with this condition (Geretsegger et al., 2015). The children had access to five keyboards and a variety of percussion instruments such as tambourines, drums, triangles, xylophones and shakers. During the improvisation part of the sessions the children had the freedom to choose from the instruments available and who in the group they wanted to work, or whether they preferred to work alone. This ensured the children had autonomy over their musical choices, which can lead to an improved eudemonic wellbeing (Ryan, Huta, \& Deci, 2008).

Performing offered the children to opportunity to present what they had created and receive some positive feedback (from the teacher and other group members) for their hard work within a safe, supportive and friendly environment. This has been linked to improving self-esteem (Chang, Chen, Beckstead, \& Yang, 2018).

\subsubsection{Questionnaires}

To quantitatively evaluate children's wellbeing (in relation to their perceived belonging, self-esteem and empathy), a 14-item self-report questionnaire (CWQ) was prepared for this study (Appendix E). Statements from three separate questionnaires designed to measure belonging (5 items), empathy (5 items) and self-esteem ( 4 items) were adapted to be suitable for the sample of children, who marked their answers using a 5-point Likert scale (Never (0), Not much of the time (1), Some of the time (2), Quite a lot of the time (3), All of the time (4)).

Statements relating to belonging were taken from the Interpersonal Support Evaluation List (Cohen, Mermelstein, Kamarck, \& Hoberman, 1985). Statements relating to self-esteem were taken from the Self-esteem Inventory (Coopersmith, 1987), and statements relating to empathy were taken from Reniers, Corcoran, Drake, Shryane \& Völlm (2011) measure of affective and cognitive empathy. In 
total the CWQ included 14 questions which was deemed short enough to maintain the children's attention and focus.

The questionnaire the parents or caregivers completed about the children (PQ) in the intervention group comprised of the same questions, but the wording was adapted so it was relevant for them to score in relation to their child (Appendix F). At the end of each questionnaire, a space was provided for the children and parents/caregivers to write any other comments.

\subsubsection{Musicality}

The Primary Measures of Music Audiation (PMMA; Gordon, 1986) test was used to measure the musicality of the children taking part in the intervention group. This was administered at the start of the first intervention session and at the end of the final intervention session. The PMMA is a "same/different" paradigm that measures a child's ability to evaluate tonal and rhythmic patterns which were played to group from recordings. On the answer sheet, the children draw a circle around the pair of faces that are the same if the two musical phrases sound the same, or the two faces that are different if the phrases sound different. Each factor comprises of 40 items and takes 12 minutes to complete. Raw scores from the tonal and rhythm test were combined to create a composite score and transformed into percentiles according to the PMMA scoring manual.

Scores from the PMMA test can fluctuate depending on the children's level of attention when taking the test. The test-retest reliability for Year 3 (7-8 years) is $.76(\mathrm{SE}=2.3)$ and for Year 4 (8 - 9 years), $.73(\mathrm{SE}=2.1)$. The PMMA was used to ascertain whether the children in the intervention group had improved their musicality over the period of the intervention.

\subsection{Qualitative Measures}

\subsubsection{Brainstorming}

During each session, a "brainstorming" group activity took place to introduce the emotion to be explored to the children. The teacher facilitated this task by asking:

1) What is [emotion]?

2) Can you think of a time when you felt [emotion]?

3) What did you do?

4) How did it feel?

Children spoke their responses out loud and then wrote their responses on the flip chart paper using the colour felt tip they chose to depict that emotion. One musical excerpt demonstrating the emotion was then played and the children had a (teacher led) discussion about whether they thought it represented the emotion. The group then discussed the following question: If you were to describe [emotion] through music, how would it sound? The children spoke their response and then wrote their thoughts on the flip chart.

\subsubsection{Observations}

Comments the children made when they were choosing instruments, working 
within their group or during the brainstorming activity were recorded by the research assistant while the teacher ran the sessions. Information was captured about which children chose to perform at the end of each session and the children's choices of who they worked with (whether they chose to work on their own, in pairs or groups).

\subsubsection{Storyboards and Recordings}

In the final session, the children created a storyboard using the emotions they had explored during the intervention. Children recorded these using the story board template. Children were free to complete their story boards however they wanted, and these data were collected at the end of the session. Audio recordings of the children's performances were made (see Appendix H).

\section{Results}

\subsection{Missing Data and Statistical Approach}

From the intervention group, one participant was unable to complete the PMMA on both occasions, and two other participants either did not complete the pre or post PMMA. These three children were categorised as having special educational needs (SEN). As noted in previous studies (Rose, Jones Bartoli, \& Heaton, 2019), it can be difficult for children with SEN to maintain concentration for the period required to complete this measure. Furthermore, not all the children answered all the items on the questionnaire each week. Therefore, the $n$ is provided for each statistic for transparency. Similarly, it is difficult to administer questionnaires successfully with the parents and caregivers of children in school studies. In this study, eight parents (all from the intervention group) completed their child's wellbeing questionnaire in Week 1, but only four parents completed their questionnaires again in Week 6. For completeness, the paired sample t test results of this measure are included herein, though the results must be considered as within-subject change over time in light of the large amount of missing data.

Statistical analyses were conducted using the appropriate test for each aspect including Pearson's bivariate correlations, paired sample T tests and repeated measures ANOVA. All analyses were conducted using SPSS v25 and v26. The alpha $p$ value was set at $.05, S D=$ standard deviation and $n s=$ not significant.

\subsubsection{Children's Wellbeing Questionnaire (CWB)}

To test whether the three measured factors of Self-esteem, Belonging and Empathy were associated, and could therefore be considered as conceptually capturing "Wellbeing", one-tailed Pearson bivariate correlations were carried out on mean of Week 1 scores for the whole sample for the three factors.

From the children's self-report questionnaire data, Self-esteem was significantly correlated with Belonging $(r(28), p=.02)$ and there was a significantly associated relationship between Empathy and Belonging $(r(24), p=.04)$. However, no significant relationship was found between Self-esteem and Empathy $(r(25), p=.32)$. 
For the parent questionnaire (PQ), none of the three factors correlated significantly: Self-esteem $\sim$ Empathy $(r(8), p=.10)$, Self-esteem $\sim$ Belonging $(r(8), p$ $=.20)$, Empathy $\sim$ Belonging $(r(8), p=.22)$.

Consequently, an overall score for Wellbeing was not deemed conceptually valid. The mean and standard deviation for the three factors are provided in Table 2 and these were used for separate subsequent analyses ${ }^{1}$.

For the between-group analyses for the children's self-report questionnaire, comparing Week 1 with Week 6 using RM AMOVA, no significant main effect of time, or interventions between groups was revealed (Self-esteem; Main Effect $p=.45$, Interaction, $p=.28$, Empathy; Main Effect $p=.58$, Interaction, $p=.38$, Belonging; Main Effect $p=.33$, Interaction, $p=.84$ )

As the data showed the intervention group scores increased, but the control group scores did not, within-subject paired sample t tests comparing week 1 and week 6 for the intervention group only were conducted. However, these also did not reveal a significant change during the time period (Self-esteem, $p=.24$, Empathy, $p=.35$, Belonging, $p=.53$ ).

For the parent questionnaire (PQ), due to the small $n$ (i.e., the four parent/caregivers who completed the questionnaire form the intervention group), paired sample $t$ tests were also used to compare Week 1 to Week 6 . A significant increase in the perceived sense of Belonging of their child was revealed, $t(3)=$ $13.32, p=.001$. The mean score increased from $3.90(S D=.66)$ to $11.69(S D=$ 1.68). No significant changes over time were revealed for Self-esteem $(p=.18)$,

Table 2. Children and parent/caregiver wellbeing questionnaire scores.

\begin{tabular}{|c|c|c|c|c|c|c|c|c|c|c|c|}
\hline & & \multicolumn{5}{|c|}{ Week 1} & \multicolumn{5}{|c|}{ Week 6} \\
\hline & & $N$ & $M$ & $S D$ & Min & Max & $N$ & $M$ & $S D$ & Min & Max \\
\hline \multicolumn{12}{|c|}{ Children (CWQ) } \\
\hline & Intervention & 15 & 3.60 & .68 & 2.20 & 4.60 & 17 & 3.80 & 1.06 & 1.80 & 5.00 \\
\hline \multirow[t]{3}{*}{ Self-esteem } & Control & 14 & 3.63 & .79 & 2.40 & 4.80 & 15 & 3.57 & .62 & 2.00 & 4.40 \\
\hline & Whole Sample & 29 & 3.61 & .72 & 2.20 & 4.80 & 32 & 3.69 & .88 & 1.80 & 5.00 \\
\hline & Intervention & 13 & 3.50 & .70 & 2.25 & 4.75 & 17 & 3.69 & .89 & 1.50 & 4.75 \\
\hline \multirow[t]{3}{*}{ Empathy } & Control & 13 & 3.69 & .72 & 2.25 & 5.00 & 15 & 3.68 & .61 & 2.25 & 4.25 \\
\hline & Whole Sample & 26 & 3.60 & .70 & 2.25 & 5.00 & 32 & 3.69 & .76 & 1.50 & 4.75 \\
\hline & Intervention & 14 & 3.74 & .69 & 2.60 & 5.00 & 17 & 3.64 & .95 & 1.40 & 5.00 \\
\hline \multirow[t]{2}{*}{ Belonging } & Control & 14 & 3.86 & .69 & 2.80 & 5.00 & 15 & 3.55 & .76 & 1.60 & 4.60 \\
\hline & Whole Sample & 28 & 3.80 & .68 & 2.60 & 5.00 & 32 & 3.59 & .85 & 1.40 & 5.00 \\
\hline \multicolumn{12}{|c|}{ Parent/Caregiver (PQ) } \\
\hline Self-esteem & & 8 & 4.15 & .54 & 3.00 & 4.80 & 4.00 & 4.00 & .54 & 3.20 & 4.40 \\
\hline Empathy & $\begin{array}{l}\text { Intervention } \\
\text { Group Only }\end{array}$ & 8 & 3.66 & .87 & 2.50 & 5.00 & 4.00 & 3.69 & .75 & 2.75 & 4.50 \\
\hline Belonging & & 8 & 3.75 & .52 & 3.20 & 4.80 & 4.00 & 4.00 & .59 & 3.40 & 4.80 \\
\hline
\end{tabular}

${ }^{1}$ Data was collected each week for the intervention group, though the level of completion of the questionnaires was not consistant. These data can be found in the Supplementary Table S1. 
or Empathy $(p=.09)$.

\subsubsection{PMMA}

Age was not a significant factor in PMMA performance either at Time $1(p>.1)$ or over time $(p>.7)$. Therefore, the intervention group as a whole was compared on the PMMA from Week $1(M e a n=66.06, S D 19.87)$ to Week 6 (Mean= $77.00, S D$ 16.42). A significant increase was revealed across time for the composite percentile score on PMMA, $t(13) 3.53, p>.01$. This suggests the level of musicality in the music club participants (which was above average at Time 1) increased significantly during the intervention.

Pearson bivariate correlations were used to investigate the associations between the improvement in musicality (the mean difference between PMMA scores over time) and wellbeing scores (the mean difference in self-report scores over time). A significant relationship was found between PMMA and Belonging, $r(8)=.78, p=.04$, but not between PMMA and Self-esteem $(p=.58)$ or PMMA and Empathy $(p=.28)$.

\subsection{Qualitative Data}

\subsubsection{Observations}

Table 3 shows the changes observed in the children's grouping behaviour over the interventions. During the first week of the intervention the children mostly worked independently, but by the final session only two children chose to work alone. During the intervention to begin with participant 7 was reluctant to join in with other children. Participant 7 has been diagnosed with ASD. During the sadness session participant 5 offered participant 7 the chance to join in with him in a pair. Throughout the rest of the sessions these two participants worked together, often complementing each other's improvisations and beginning to turn take with this. Participant 5 reminded participant 7 "remember to stick together" in the anger session.

At the end of the questionnaire the children had the option to write any other comments about the intervention. In week one participant 19 wrote "I am not happy most of the time". This is in comparison to week six where she wrote "I now like the keyboards". During the week on anger, two participants wrote comments in relation to their feelings about belonging: Participant 6 wrote, "I

Table 3. Observations of grouping during sessions.

\begin{tabular}{cccc}
\hline Week & Children working Alone & Number of Pairs & Number of Groups \\
\hline 1 & 6 & 4 & 1 \\
2 & 5 & 4 & 1 \\
3 & 5 & 3 & 2 \\
4 & 4 & 5 & 1 \\
5 & 3 & 7 & 0 \\
6 & 2 & 6 & 1
\end{tabular}


feel happy", and Participant 8 wrote, "I feel I am part of this school environment and everyone is kind and helpful to me".

In the final week, which focused on the storyboards, some of the children chose to write a sentence about the music club in general. Participant 4 wrote, "I enjoyed it". Participant 6 expressed an interest to continue with the music club, "We should do some more music club and I have enjoyed everything". This was seconded by participant 8 who wrote "I really liked the group and I also loved playing instruments and mates. I also think we could do love as well”. Here this participant had referred to enjoying the music club but also the fact that they have enjoyed working with friends and suggested another emotion they would like to explore.

At the start of the sessions many of the children were reluctant to perform their improvisations and it took a lot of encouragement for the children to feel confident to perform what they had created. By the end of the six-week period, the children were more enthusiastic about performing and the group was very supportive, often praising one another for their performances.

\subsubsection{Brainstorming}

Figure 1 shows examples of data (i.e., the flip charts) from the brainstorming activities that began each session. Each emotion was discussed (teacher led) in
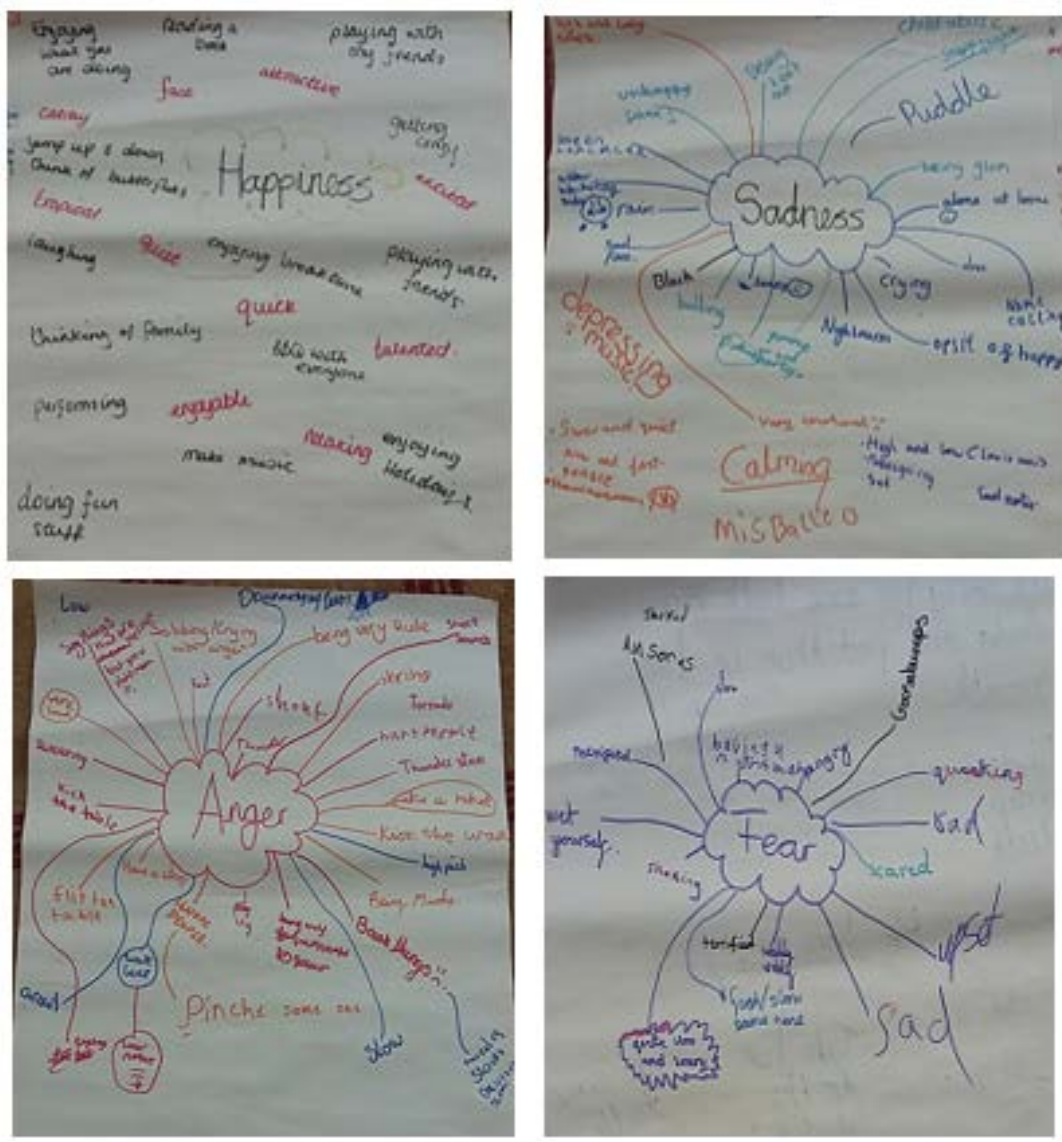

Figure 1. Examples of brainstorming activity. 
terms of what action the children might be doing when they felt that emotion, or something they do which might make them feel in this way. Children were encouraged to think about this in terms of how that emotion might sound through music. In the first sessions pupils often described the emotion using synonyms for that emotion. When discussing the emotion "Joy" participant three said, "It just sounds like happy and fun". With sadness children were focusing on when they might feel sad as to applying this to music, "when I have nightmares, it's like rain". In the session focusing on anger and disgust the children began to apply this more to the music, "loud banging sounds, it might sound squishy". The development of their descriptive language became more apparent in the final emotion session on fear where children were more vocal and reasoning about their musical choices. For example, pupil 24 said, “we can't have two high pitched things" when herself and her chosen partner was experimenting with which instruments to use. When engaging within the class discussion about the emotion of fear the children were referring to where they have heard this emotion before. For example, pupil 9 said "It's like dun, dun duhh then something bad happens", referring to where she had heard a "scary" melody before.

\subsubsection{Storyboards and Recordings}

In the final session, the children brought together the work they had completed on each emotion and applied their knowledge by creating their own story boards. All children created music to accompany their story boards. Recordings of the children's interpretation of each emotion (see Appendix $\mathrm{H}$ ) and the storyboards were made at the end of the sessions if the children felt confident enough to perform to the rest of the group. Recordings 1 and 2 provide audio examples of the children's interpretation of fear (see Appendix H).

When writing their storyboards some children chose to draw and write the emotions, as shown in Figure 2. The recorded music for this storyboard (Recording 3, see Appendix H) demonstrates the children's transitions through the emotions using music.

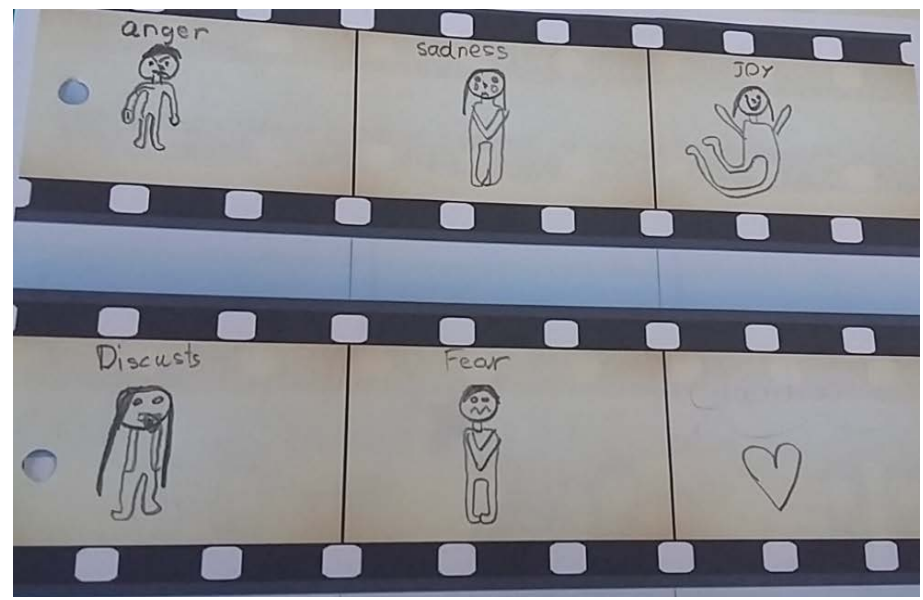

Figure 2. Story board with drawn and written emotions associated with recording 3. 
Other children chose to include how the emotions would sound through describing the music (see Figure 3 and Figure 4).

One pairing chose to include some other emotional states that were not included within the intervention (see Figure 5). They were able to interpret how these emotions would sound to them.

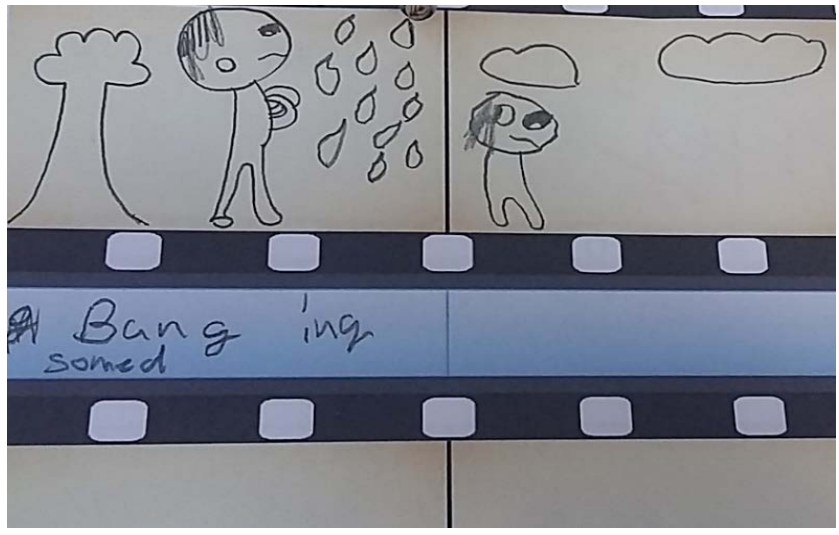

Figure 3. Story board representing sadness (no recording).

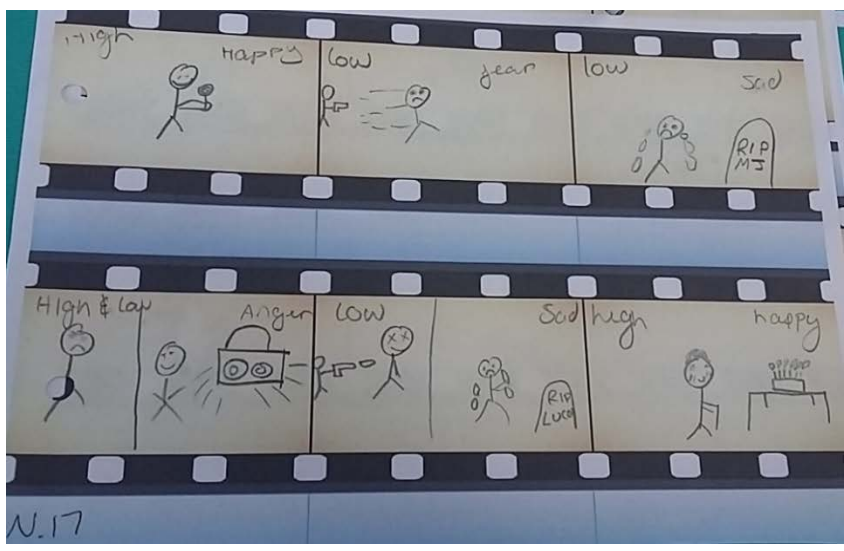

Figure 4. Example of storyboard linking musical sounds to emotions.

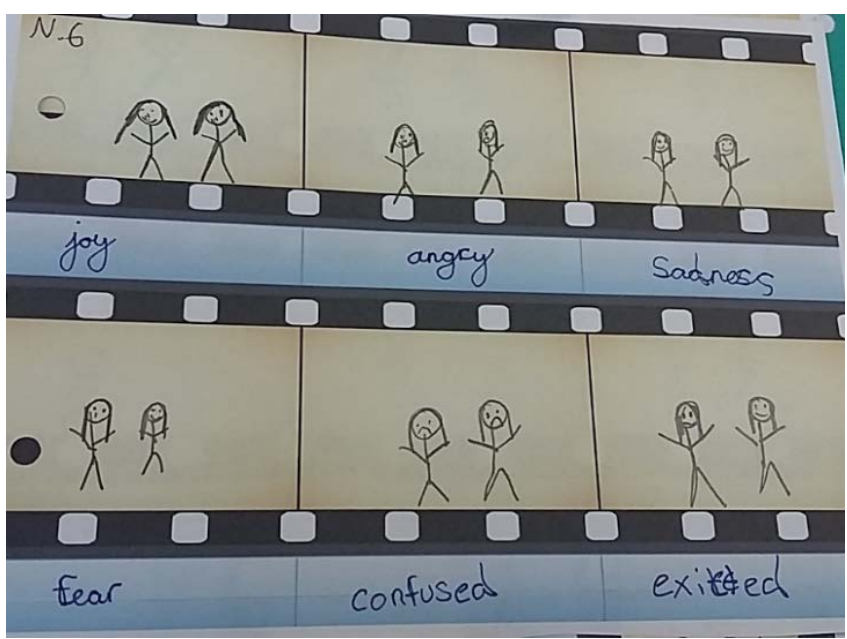

Figure 5. Example of exploring emotions through storyboards. 
Another pair chose to complete their final story board on the emotion of sadness (Recording 4, see Appendix $\mathrm{H}$ ). Rather than drawing pictures of the emotions, they chose to record this as musical notes, as depicted in Figure 6. In the recording you can hear their interpretation of the emotion for sadness using some of the ideas discussed at the start of the sessions (see Figure 1).

\section{Discussion}

The aim of this study was to create a brief music intervention to explore emotions to support children's wellbeing. Wellbeing was conceptualised as including self-esteem, empathy and belonging in this context. The children's levels of wellbeing were compared to a control group who did not participate in the voluntary "music club" through which the intervention was delivered. The study hypothesised that the children who took part in the programme would have: 1) improved their musicality according to scores on the PMMA, and 2) increased their wellbeing (i.e., sense of belonging, empathy and self-esteem) compared to a control group who did not take part in the music club. The use of mixed methods was important as it provided a rich set of data to explore the efficacy of the intervention and explain findings from the quantitative data. The merits and issues of both approaches are discussed in the following section.

The significant increase in the PMMA percentile scores in the intervention group suggested that the children who participated in the music club did gain musical skills. However, as the mean percentile score was already above average in the group, it is likely that the sample was bias towards higher interest and/or levels of musicality due to the self-selection process. It would be necessary to also test the control group using the PMMA to demonstrate a causal development, i.e., that the higher level of musical engagement increased musical ability over time (Schellenberg, 2019). Gordon (1986) suggests musical ability increases over time up to the age of nine years in children, if and when the children experience

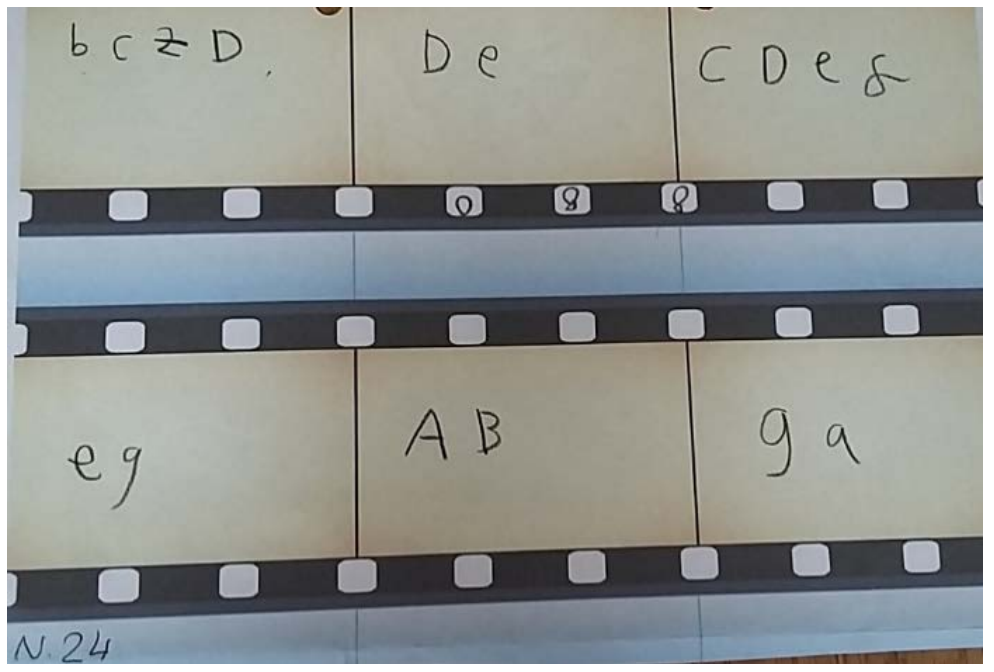

Figure 6. Example of storyboard where pair chose to write the notes rather than draw pictures. This is associated with recording 4 . 
a musically enriched environment. In the school in which the intervention took place, group singing in assemblies is a common occurrence (two assemblies dedicated to singing, and a third when a song is sung at the end). Therefore, future studies should include the PMMA, or another measure of children's musicality, in order to establish pre/post changes in relations to musical abilities.

The second issue in relation to the collection of the quantitative data is the nature of self-report questionnaires, and in particular the poor level of questionnaire completion by the parents/caregivers. Conducting research in educational settings can be difficult and there is often a high attrition rate (Mishna, McInroy, Daciuk, \& Lacombe-Duncan, 2017). With this study there was a high initial sign-up rate, however this did decline. One of the main difficulties was maintaining the children's engagement (Lamont, 2012) as the project took place in the final term of the year (May-July), during a year of unusually good weather (for the UK summer). This meant that at the end of music club, the children wanted to play outside rather than complete the questionnaires, and the parents/caregivers were inundated with end of term activities and other forms to complete. A potential way to overcome these difficulties for future studies would be to request a ten-minute session with the parents before the intervention (during which they could ask questions but also fill in the questionnaire), and to provide a performance session at the end of the intervention (see Figure 7 for revised intervention schedule) and possibly conduct it during the start of, rather than at the end of, a term.

Regarding the self-report nature of the questionnaires, some researchers have suggested that the level of the child's reading, language comprehension, memory, concentration, thinking and self-reflection can all hinder their understanding

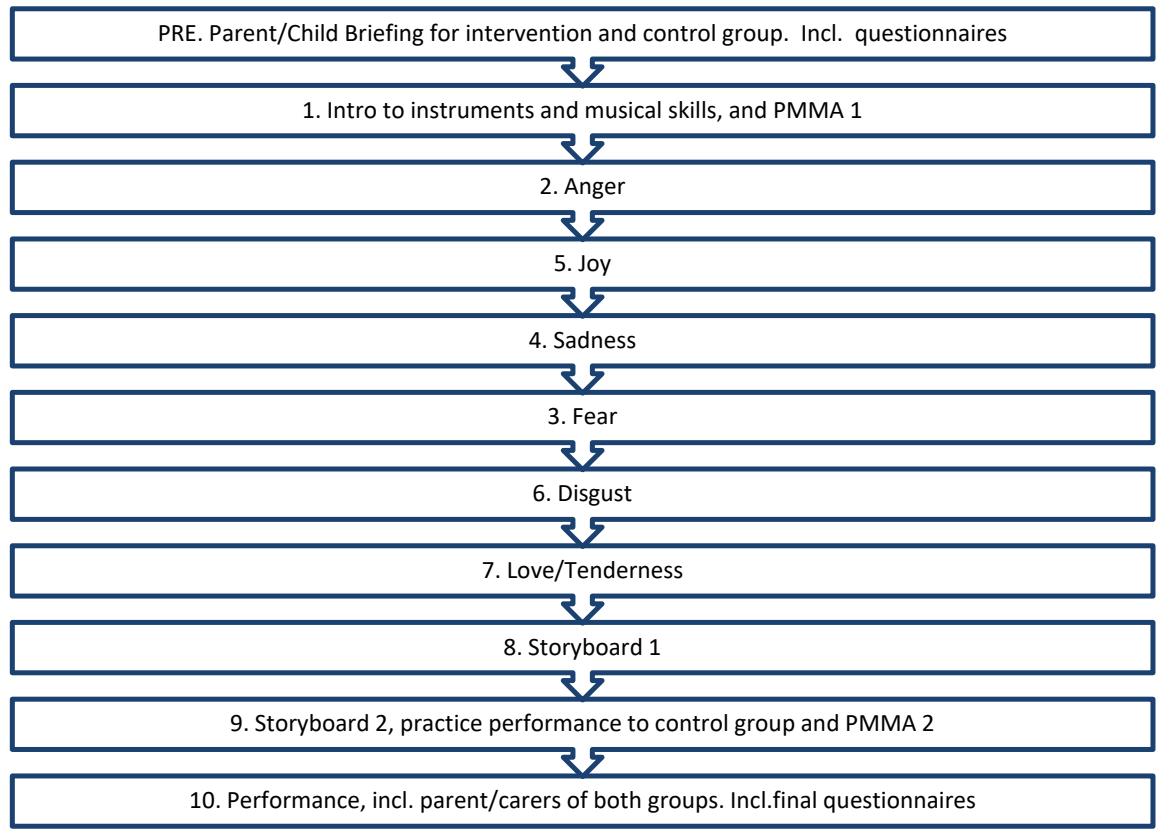

Figure 7. Revised intervention schedule. 
thereby invalidating self-report questionnaires under the age of nine years (Kuijpers, Otten, Vermulst, \& Engels, 2014). McGurk and Glachan (1988) suggest that self-report requires children to communicate their thoughts and feelings in an adult manner which may be unreliable, or children may choose extreme responses on Likert scales (Chambers \& Johnston, 2002). As noted by Tobia, Greco, Steca and Marzocchi (2019), the discrepancies between other people's perceptions of children's wellbeing in comparison to the children's perception of their own wellbeing is well known, and multiple viewpoints are required to provide better understanding. Future studies could consider using a more general brief measure of wellbeing, such as the World Health Organisation five item scale (Bech, 2004) which has been validated with children. This may reduce participant demand and enable more consistent weekly data collection that could then be used in repeated measures analyses within-subjects.

The innovative use of qualitative data gave a wider insight into the changes in the children's sense of belonging. The observations about the children's choice of groupings suggests that the children have developed a stronger sense of belonging within the group as the children felt more comfortable to work within a group by the final session. This supports the idea that music promotes positive, group cohesion as suggested by Parker (2010). As the intervention group become more supportive of each other, this may have had a positive impact on their self-esteem over time. Previous research has shown that music can improve children's self-esteem (Zapata and Hargreaves, 2017; Rickard, Appelman, James, Murphy, Gill, and Bambrick, 2013). These studies took place over an 18-week, suggesting longer interventions are required to reinforce positive change.

Overall, the intervention was a success in terms of the children's enjoyment and engagement in the sessions. McPherson (2001) reports that children take part in music because it is fun and enjoyable. It was clear from the children's comments at the end of session six that they enjoyed the sessions, and some expressed a view that they would like the intervention to carry on in the future. Clarke et al. (2014) suggests further insight regarding both positive and negative aspects of the intervention from the children's perspective can be obtained by recording the children's answers to the following questions at the end of each session: What did you like about the programme? What did you dislike? What has the programme taught you?

To improve this intervention for future studies, the following recommendations are made:

1) Musical skill differentiation.

During the first session it became clear that some of the children had very little and varied experience with using the musical instruments. This lack of musical skill affected the children's confidence and inhibited performance at the end of the first session. Some of the children needed lots of encouragement to engage with the instruments at all at first, but as they become familiar with the instruments, and with each other, they also become more confident with their own 
musical ability. This led to higher levels of confidence for improvisation and also for composition as the music the children were creating became more like the emotion they were describing. Therefore, to develop the intervention further, the first session should be a baseline musical session covering the elements of music (dynamics, timbre, tempo, pitch, structure and texture) and how the instruments can be used to create these. This will ensure all children within the intervention have a better understanding of how they can use the instruments to engage in meaningful improvisations within the emotion focused sessions.

2) Emotion and language differentiation.

Within the intervention, the children found some emotions easier to describe through music than others. For example, anger was easier to create music for than sadness or joy. At the start of each session, only one example song was played to the children. Future trials could play two songs to explore differences which may help clarify the concepts of the emotions for the children. The children found the emotion of disgust an especially difficult concept to describe. This could be because disgust is an emotion where you often need an object to relate this to (Cespedes-Guevara and Eerola, 2018). To help the children with this concept they were encouraged to create a piece of music about something they disliked, which they found an enjoyable challenge. For example, one of the children particularly disliked eating broccoli so the group discussed the texture of broccoli and made squishing and squelching sounds. If this intervention was to be trialed again, it would be recommended to alter the session order, and include love or tenderness (as suggested by one of the children) prior to disgust to ensure the basic emotions highlighted by Juslin (2013) are covered first. The first emotion to consider could be anger, as this concept was easier for the children to create sounds for, followed by joy, sadness, fear, love or tenderness and finally disgust.

Finally, the children felt rushed when creating their emotional story boards at the end of the intervention. Therefore, more time (two weeks) should be dedicated to this to ensure all children are able to develop their creations. As suggested in the revised ten-week intervention schedule (see Figure 7), a performance session to which the parent/caregivers were invited too would provide an inclusive sense of shared goals which may be important as previous research has shown that performance is a key factor in improving self-esteem (Chang, Chen, Beckstead, \& Yang, 2018).

During the COVID-19 pandemic, many children have felt increased isolation and loneliness (Loades et al., 2020). Music has been used as a tool for encouraging health related behaviours (Lehman, 2020), for decreasing isolation and improving connectedness, and teaching and learning in music education holds promise for recovery and resilience as we move forwards (Cabedo-Mas, ArriagaSanz, \& Moliner-Miravet, 2020; Chiu, 2020; Daubney \& Fautley, 2020; Gatera \& Pavarini, 2020). Though further work is required in terms of establishing more robust questionnaires for research purposes, we present this pilot study not only as a way to improve children's musicality, but also as an example of how innova- 
tive techniques can be used to create engaging music-based activities that can encourage children to explore their emotions in general, and generate a sense of belonging; a potentially useful application of arts-in-health for teachers and practitioners as we emerge from these difficult times. We welcome potential collaborations with other researchers interested in the use of music and the arts in education who wish to replicate and/or develop this intervention.

\section{Conclusion}

Music is used all over the world to communicate ideas, develop and represent identity, and to express meanings (Brown \& Jordania, 2013; Cespedes-Guevara \& Eerola, 2018). During this intervention, the children used music to tune into the emotion they were exploring, paying careful attention to which instrument would be the best for describing the sound of the emotion. The innovative mixed methods approach helped provide a complete picture that neither psychological measurement, nor quantitative approaches could capture alone. This resulted in an understanding of how this brief music intervention supported the development of a sense of belonging as experienced by the children and noticed by the parents. In light of the difficulties caused by the COVID-19 pandemic, the reporting of this pilot project may guide future implementations of music-based interventions by teachers for children in schools, helping regain a sense of belonging and explore core emotions through of music making and listening.

\section{Author Note}

This study was undertaken by Elizabeth Liddiard as her MSc (Psychology) research project at the University of Hertfordshire, supervised by Dr Dawn Rose. The project concept was inspired by the animated children's film "Inside Out" (Docter \& Del Carmen, 2015) which was developed in consultation with psychologists to help children explore the nature of five core emotions (joy, sadness, anger, fear and disgust). The results of the study were disseminated by Elizabeth Liddiard on 10th November 2018 at the Collaborative Approaches to Music and Wellbeing Research Conference (SEMPRE), University of Leeds and written up for publication by Dawn Rose.

\section{Conflicts of Interest}

The authors declare no conflicts of interest regarding the publication of this paper.

\section{References}

Ball, P. (2010). The Music Instinct: How Music Works and Why We Can't Do without It. London: The Bodley Head.

Bech, P. (2004) Measuring the Dimension of Psychological General Well-Being by the WHO-5. Quality of Life Newsletter, 32, 15-16.

Bonell, C., Humphrey, N., Fletcher, A., Moore, L., Anderson, R., \& Campbell, R. (2014). Why Schools Should Promote Students' Health and Wellbeing. BMJ, 348, g3078. 
https://doi.org/10.1136/bmj.g3078

Brown, S., \& Jordania, J. (2013). Universals in the World's Musics. Psychology of Music, 41, 229-248. https://doi.org/10.1177/0305735611425896

Bugos, J. A., Perlstein, W. M., McCrae, C. S., Brophy, T. S., \& Bedenbaugh, P. H. (2007). Individualized Piano Instruction Enhances Executive Functioning and Working Memory in Older Adults. Aging \& Mental Health, 11, 464-471. https://doi.org/10.1080/13607860601086504

Cabedo-Mas, A., Arriaga-Sanz, C., \& Moliner-Miravet, L. (2020). Uses and Perceptions of Music in Times of COVID-19: A Spanish Population Survey. Frontiers in Psychology, 11, Article ID: 606180. https://doi.org/10.3389/fpsyg.2020.606180

Central Bedfordshire Council (2015). Parkside Ward Profile. https://www.centralbedfordshire.gov.uk/migrated images/parkside tcm3-7810.pdf

Cespedes-Guevara, J., \& Eerola, T. (2018). Music Communicates Affects, Not Basic Emotions-A Contructionist Account of Attribution of Emotional Meanings to Music. Frontiers in Psychology, 9, 215. https://doi.org/10.3389/fpsyg.2018.00215

Chambers, C. T., \& Johnston, C. (2002). Developmental Differences in Children's Use of Rating Scales. Journal of Pediatric Psychology, 27, 27-36. https://doi.org/10.1093/jpepsy/27.1.27

Chang, B. Chen, B. Beckstead, J., \& Yang, C. (2018). Effects of a Music-Creation Programme on the Anxiety, Self-Esteem and Quality of Life of People with Severe Mental Illness. International Journal of Mental Health Nursing, 27, 1066-1076.

https://doi.org/10.1111/inm.12414

Chiu, R. (2020) Functions of Music Making under Lockdown: A Trans-Historical Perspective across Two Pandemics. Frontiers in Psychology, 11, Article ID: 616499. https://doi.org/10.3389/fpsyg.2020.616499

Choi, A., Lee, M., \& Lee, J. (2010). Group Music Intervention Reduces Aggression and Improves Self esteem in Children with Highly Aggressive Behavior: A Pilot Controlled Trial. Evidence-Based Complementary and Alternative Medicine, 7, Article ID: 465730. https://doi.org/10.1093/ecam/nem182

Clarke, A. M., Sixsmith, J., \& Barry, M. M. (2014) Evaluating the Implementation of an Emotional Wellbeing Programme for Primary School Children Using Participatory Approaches. Health Education Journal, 74, 578-593

Clements-Cortés, A., \& Chow, S. (2018). Enhancing Self-Esteem in the Music Classroom. The Canadian Music Educator, 59, 23-26.

Clift, S. (2010). Let the Music Play. British Journal of Wellbeing, 1, 15-17. https://doi.org/10.12968/bjow.2010.1.1.47699

Clift, S. M., \& Hancox, G. (2001). The Perceived Benefits of Singing: Findings from Preliminary Surveys of a University College Choral Society. The Journal of the Royal Society for the Promotion of Health, 121, 248-256.

Clift, S., Hancox, G., Morrison, I., Hess, B., Kreutz, G., \& Stewart, D. (2007). Choral Singing and Psychological Wellbeing: Findings from English Choirs in a Cross-National Survey Using the WHOQOL-BREF. In Proceedings of the International Symposium on Performance Science (pp. 201-207). AEC.

Cohen, M. L. (2007). Explorations of Inmate and Volunteer Choral Experiences in a Prison-Based Choir. Australian Journal of Music Education, 1, 61-72.

Cohen, S., Mermelstein, R., Kamarck, T., \& Hoberman, H. M. (1985). Measuring the Functional Components of Social Support. In I. G. Sarason, \& B. R. Sarason (Eds.), Social Support: Theory, Research, and Applications (pp. 73-94). The Hague, Netherlands: 
Martinus Nijhoff. https://doi.org/10.1007/978-94-009-5115-0 5

Coopersmith, S. (1987). Self-Esteem Inventory. Palo Alto, CA: Consulting Psychotogists Press.

Costa-Giomi, E. (2004). Effects of Three Years of Piano Instruction on Children's Academic Achievement, School Performance and Self-Esteem. Psychology of Music, 32, 139-152. https://doi.org/10.1177/0305735604041491

Darbyshire, P., MacDougall, C., \& Schiller, W. (2005). Multiple Methods in Qualitative Research with Children: More Insight or Just More? Qualitative Research, 5, 417-436. https://doi.org/10.1177/1468794105056921

Daubney, A., \& Fautley, M. (2020). Editorial Research: Music Education in a Time of Pandemic. British Journal of Music Education, 37, 107-114. https://doi.org/10.1017/S0265051720000133

Dingle, G., \& Fay, C. (2013). Tuned in: A Brief Music Emotion Regulation Intervention for Young Adults. Psychology of Music, 45, 513-529. https://doi.org/10.1177/0305735616668586

Docter, P., \& Del Carmen, R. (2015). Inside Out. Walt Disney Studios Motion Pictures.

Eerola, T. (2018). Music and Emotions. In R. Bader (Ed.), Springer Handbook of Systematic Musicology (pp. 539-554). Berlin, Heidelberg: Springer.

https://doi.org/10.1007/978-3-662-55004-5 29

Ekkekakis, P. (2013). The Measurement of Affect, Mood, and Emotion: A Guide for Health-Behavioral Research. Cambridge: Cambridge University Press. https://doi.org/10.1017/CBO9780511820724

Faulkner, S., Wood, L., Ivery, P., \& Donovan, R. (2012). It Is Not Just Music and Rhythm... Evaluation of a Drumming Based Intervention to Improve the Social Wellbeing of Alienated Youth. Children Australia, 37, 31-39.

Foster, M., \& Jenkins, J. (2017) Does Participation in Music and Performing Arts Influence Child Development? American Educational Research Journal, 54, 399-443. https://doi.org/10.3102/0002831217701830

Fredrickson, B. L., \& Joiner, T. (2002). Positive Emotions Trigger Upward Spirals toward Emotional Well-Being. Psychological Science, 13, 172-175. https://doi.org/10.1111/1467-9280.00431

Gatera, G., \& Pavarini, G. (2020). COVID-19: what Is Next for Public Health. The Lancet, 395, 542-545. https://doi.org/10.1016/S0140-6736(20)30374-3

Geretsegger, M., Holck, U., Carpente, J. A., Elefant, C., Kim, J., \& Gold, C. (2015). Common Characteristics of Improvisational Approaches in Music Therapy for Children with Autism Spectrum Disorder: Developing Treatment Guidelines. The Journal of $\mathrm{Mu}$ sic Therapy, 52, 258-281. https://doi.org/10.1093/jmt/thv005

Gilboa, A., Bodner, E., \& Amir, D. (2006). Emotional Communicability in Improvised Music: The Case of Music Therapists. Journal of Music Therapy, 43, 198-225. https://doi.org/10.1093/jmt/43.3.198

Gordon, E. E. (1986). Manual for the Primary Measures of Music Audiation and the Intermediate Measures of Music Audiation. Chicago, IL: G.I.A. Publications Inc.

Groarke, J., \& Hogan, M. (2016). Enhancing Wellbeing: An Emerging Model of the Adaptive Functions of Music Listening. Psychology of Music, 44, 769-791. https://doi.org/10.1177/0305735615591844

Hallam, S. (2010). The Power of Music: Its Impact on the Intellectual, Social and Personal Development of Children and Young People. International Journal of Music Education, 28, 269-289. https://doi.org/10.1177/0255761410370658 
Henley, D. (2011). Music Education in England: A Review by Darren Henley for the Department for Education and the Department for Culture, Media and Sport. Music Education in England: A Review for the Department for Education and the Department for Culture, Media and Sport. DfE-00011-2011.

Henley, D. (2016). The Arts Dividend: Why Investment in Culture Pays. London: Elliott and Thompson Limited.

Hennessy, S. (2018). Improving Primary Teaching: Minding the Gap. In G. E. McPherson, \& G. F. Welch, Eds., Music and Music Education in People's Lives: An Oxford Handbook of Music Education (Vol. 1, pp. 265-275). Oxford: Oxford University Press.

Hietolahti-Ansten, M., \& Kalliopuska, M. (1990). Self-Esteem and Empathy among Children Actively Involved in Music. Perceptual and Motor Skills, 71, 1364-1366. https://doi.org/10.2466/pms.1990.71.3f.1364

Hyde, K. L., Lerch, J., Norton, A., Forgeard, M., Winner, E., Evans, A. C., \& Schlaug, G. (2009). Musical Training Shapes Structural Brain Development. Journal of Neuroscience, 29, 3019-3025. https://doi.org/10.1523/JNEUROSCI.5118-08.2009

Juslin, P. (2013). What Does Music Express? Basic Emotions and Beyond. Frontiers in Psychology, 4, 596. https://doi.org/10.3389/fpsyg.2013.00596

Juslin, P. N., \& Laukka, P. (2003). Communication of Emotions in Vocal Expression and Music Performance: Different Channels, Same Code? Psychological Bulletin, 129, 770814. https://doi.org/10.1037/0033-2909.129.5.770

Juslin, P. N., \& Laukka, P. (2004). Expression, Perception, and Induction of Musical Emotions: A Review and a Questionnaire Study of Everyday Listening. Journal of New Music Research, 33, 217-238. https://doi.org/10.1080/0929821042000317813

Juslin, P. N., \& Västfjäll, D. (2008). Emotional Responses to Music: The Need to Consider Underlying Mechanisms. Behavioral and Brain Sciences, 31, 559-575. https://doi.org/10.1017/S0140525X08005293

Juslin, P. N., Barradas, G., \& Eerola, T. (2015). From Sound to Significance: Exploring the Mechanisms Underlying Emotional Reactions to Music. The American Journal of Psychology, 128, 281-304. https://doi.org/10.5406/amerjpsyc.128.3.0281

Kamioka, H., Tsutani, K., Yamada, M., Park, H., Okuizumi, H., Tsuruoka, K., Honda, T., Okada, S., Park, S., Kitayuguchi, J., Abe, T., Handa, S., Oshio, T., \& Mutoh, Y. (2014) Effectiveness of Music Therapy: A Summary of Systematic Reviews Based on Randomized Controlled Trials of Music Interventions. Patient Preference and Adherence, 8 , 727-754. https://doi.org/10.2147/PPA.S61340

Kastner, M. P., \& Crowder, R. G. (1990). Perception of the Major/Minor Distinction: IV. Emotional Connotations in Young Children. Music Perception: An Interdisciplinary Journal, 8, 189-201. https://doi.org/10.2307/40285496

Kawakami, A., Furukawa, K., Katahira, K., \& Okanoya, K. (2013). Sad Music Induces Pleasant Emotion. Frontiers in Psychology, 4, 311. https://doi.org/10.3389/fpsyg.2013.00311

Kim, H., \& Kim, H. (2018). Effect of a Musical Instrument Performance Program on Emotional Intelligence, Anxiety, and Aggression in Korean Elementary School Children. Psychology of Music, 46, 440-453. https://doi.org/10.1177/0305735617729028

Kirschner, S., \& Tomasello, M. (2010). Joint Music Making Promotes Prosocial Behavior in 4-Year-Old Children. Evolution and Human Behavior, 31, 354-364.

https://doi.org/10.1016/j.evolhumbehav.2010.04.004

Koelsch, S. (2014). Brain Correlates of Music-Evoked Emotions. Nature Reviews Neuroscience, 15, 170-180. https://doi.org/10.1038/nrn3666 
Kuijpers, R., Otten, R., Vermulst, A., \& Engels, R. (2014). Reliability and Construct Validity of a Child Self-Report Instrument. The Dominic Interactive. European Journal of Psychological Assessment, 30, 40-47. https://doi.org/10.1027/1015-5759/a000166

Lamont, A. (2012) Emotion, Engagement and Meaning in Strong Experiences of Music Performance. Psychology of Music, 40, 574-594.

https://doi.org/10.1177/0305735612448510

Lamont, A., Hargreaves, D. J., Marshall, N. A., \& Tarrant, M. (2003). Young People's Music in and out of School. British Journal of Music Education, 20, 229-241. https://doi.org/10.1017/S0265051703005412

Lehman, E. T. (2020). “Washing Hands, Reaching Out”-Popular Music, Digital Leisure and Touch during the COVID-19 Pandemic. Leisure Sciences, 1-7. https://doi.org/10.1080/01490400.2020.1774013

Loades, M. E., Chatburn, E., Higson-Sweeney, N., Reynolds, S., Shafran, R., Brigden, A. et al. (2020). Rapid Systematic Review: The Impact of Social Isolation and Loneliness on the Mental Health of Children and Adolescents in the Context of COVID-19. Journal of the American Academy of Child \& Adolescent Psychiatry, 59, 1218-1239.e3. https://doi.org/10.1016/j.jaac.2020.05.009

Loersch, C., \& Arbuckle, N. L. (2013). Unraveling the Mystery of Music: Music as an Evolved Group Process. Journal of Personality and Social Psychology, 105, 777-798. https://doi.org/10.1037/a0033691

MacDonald, R. A., \& Wilson, G. B. (2014). Musical Improvisation and Health: A Review. Psychology of Well-Being, 4, 1-18. https://doi.org/10.1186/s13612-014-0020-9

Macdonald, R., Kreutz, G., \& Mitchell, L. (2014). Music, Health and Wellbeing. Oxford: Oxford University Press.

Maury, S., \& Rickard, N. (2016). Wellbeing in the Classroom: How an Evolutionary Perspective on Human Musicality Can Inform Music Education. Australian Journal of Music Education, 50, 3-15.

McGurk, H., \& Glachan, M. (1988). Children's Conversation with Adults. Children \& Society, 2, 20-34. https://doi.org/10.1111/j.1099-0860.1988.tb00323.x

McPherson, G. E. (2001). Commitment and Practice: Key Ingredients for Achievement during the Early Stages of Learning a Musical Instrument. Bulletin of the Council for Research in Music Education, 147, 122-127. https://www.jstor.org/stable/40319399

McPherson, G. E., Davidson, J. W., \& Faulkner, R. (2012). Music in Our Lives: Rethinking Musical Ability, Development and Identity. Oxford: Oxford University Press. https://doi.org/10.1093/acprof:oso/9780199579297.001.0001

Mehr, S. A., Schachner, A., Katz, R. C., \& Spelke, E. S. (2013). Two Randomized Trials Provide No Consistent Evidence for Nonmusical Cognitive Benefits of Brief Preschool Music Enrichment. PLoS ONE, 8, e82007. https://doi.org/10.1371/journal.pone.0082007

Mellor, L. (2013). An Investigation of Singing, Health and Well-Being as a Group Process. British Journal of Music Education, 30, 177-205. https://doi.org/10.1017/S0265051712000563

Mishna, F., McInroy, L. B., Daciuk, J., \& Lacombe-Duncan, A. (2017). Adapting to Attrition Challenges in Multi-Year Studies: Examples from a School-Based Bullying and Cyber Bullying Study. Children and Youth Services Review, 81, 268-271. https://doi.org/10.1016/j.childyouth.2017.08.019

Mithen, S. (2006). The Singing Neanderthals: The Origin of Music, Language, Mind and Body. London: Phoenix. 
Moreno, S., Bialystok, E., Barac, R., Schellenberg, E. G., Cepeda, N. J., \& Chau, T. (2011). Short-Term Music Training Enhances Verbal Intelligence and Executive Function. Psychological Science, 22, 1425-1433. https://doi.org/10.1177/0956797611416999

Parker, E. C. (2010). Exploring Student Experiences of Belonging within an Urban High School Choral Ensemble: An Action Research Study. Music Education Research, 12, 339-352. https://doi.org/10.1080/14613808.2010.519379

Patel, A. D. (2017). Using Music to Study the Evolution of Cognitive Mechanisms Relevant to Language. Psychonomic Bulletin \& Review, 24, 177-180. https://doi.org/10.3758/s13423-016-1088-4

Rabinowitch, T. C., Cross, I., \& Burnard, P. (2013). Long-Term Musical Group Interaction Has a Positive Influence on Empathy in Children. Psychology of Music, 41, 484498. https://doi.org/10.1177/0305735612440609

Reniers, R. L. E. P., Corcoran, R., Drake, R., Shryane, N. M., \& Völlm, B. A. (2011). The QCAE: A Questionnaire of Cognitive and Affective Empathy. Journal of Personality Assessment, 93, 84-95. https://doi.org/10.1080/00223891.2010.528484

Rickard, N. S., Appelman, P., James, R., Murphy, F., Gill, A., \& Bambrick, C. (2013). Orchestrating Life Skills: The Effect of Increased School-Based Music Classes on Children's Social Competence and Self-Esteem. International Journal of Music Education, 31, 292-309. https://doi.org/10.1177/0255761411434824

Rickard, N. S., Bambrick, C. J., \& Gill, A. (2012). Absence of Widespread Psychosocial and Cognitive Effects of School Based Music Instruction in 10 - 13-Year-Old Students. International Journal of Music Education, 30, 57-78. https://doi.org/10.1177/0255761411431399

Ritchie, L., \& Williamon, A. (2011). Primary School Children's Self-Efficacy for Music Learning. Journal of Research in Music Education, 59, 146-161. https://doi.org/10.1177/0022429411405214

Rose, D., Heaton, P., \& Jones Bartoli, A. (2018). Learning a Musical Instrument Can Benefit a Child with Special Educational Needs. Psychomusicology: Music, Mind, and Brain, 28, 71-81. https://doi.org/10.1037/pmu0000209

Rose, D., Jones Bartoli, A., \& Heaton, P. (2019). Measuring the Impact of Musical Learning on Cognitive, Behavioural and Socio-Emotional Wellbeing Development in Children. Psychology of Music, 47, 284-303. https://doi.org/10.1177/0305735617744887

Ryan, R. Huta, V., \& Deci, E. (2008). Living Well: A Self-Determination Theory Perspective on Eudaimonia. Journal of Happiness Studies, 9, 139-170. https://doi.org/10.1007/s10902-006-9023-4

Schäfer, T., Smukalla, M., \& Oelker, S. (2014). How Music Changes Our Lives: A Qualitative Study of the Long-Term Effects of Intense Musical Experiences. Psychology of Music, 42, 525-544. https://doi.org/10.1177/0305735613482024

Schellenberg, E. G. (2004). Music Lessons Enhance IQ. Psychological Science, 15, 511514. https://doi.org/10.1111/j.0956-7976.2004.00711.x

Schellenberg, E. G. (2019). Correlation = Causation? Music Training, Psychology, and Neuroscience. Psychology of Aesthetics, Creativity, and the Arts, 14, 475-480. https://doi.org/10.1037/aca0000263

Simpson, K., \& Keen, D. (2011). Music Interventions for Children with Autism: Narrative Review of the Literature. Journal of Autism and Developmental Disorders, 41, 1507 1514. https://doi.org/10.1007/s10803-010-1172-y

Sing Up (2019). https://www.singup.org/about-sing-up/

Svane, D., Evans, N., \& Carter, M. A. (2019). Wicked Wellbeing: Examining the Discon- 
nect between the Rhetoric and Reality of Wellbeing Interventions in Schools. Australian Journal of Education, 63, 209-231.

https://doi.org/10.1177/0004944119843144

Svec, C. (2018). The Effects of Instruction on the Singing Ability of Children Ages 5 to 11: A Meta Analysis. Psychology of Music, 46, 326-339. https://doi.org/10.1177/0305735617709920

Swanson, S., \& Campbell, P. (2016). Chapter 15: Informed by the Children. In A. Heble, \& M. Laver (Eds.), Improvisation and Music Education: Beyond the Classroom. Oxon: Routledge.

Thomas, M. K., Singh, P., \& Klopfenstein, K. (2015). Arts Education and the High School Dropout Problem. Journal of Cultural Economics, 39, 327-339.

https://doi.org/10.1007/s10824-014-9238-x

Tobia, V., Greco, A., Steca, P., \& Marzocchi, G. M. (2019). Children's Wellbeing at School: A Multi-Dimensional and Multi-Informant Approach. Journal of Happiness Studies, 20, 841-861. https://doi.org/10.1007/s10902-018-9974-2

Trehub, S. E., \& Hannon, E. E. (2006). Infant Music Perception: Domain-General or Domain-Specific Mechanisms? Cognition, 100, 73-99.

https://doi.org/10.1016/j.cognition.2005.11.006

Widen, S., \& Russell, J. (2008). Children Acquire Emotion Categories Gradually. Cognitive Development, 23, 291-312. https://doi.org/10.1016/j.cogdev.2008.01.002

Zapata, G. P., \& Hargreaves, D. J. (2017). The Effects of Musical Activities on the SelfEsteem of Displaced Children in Colombia. Psychology of Music, 46, 540-550. https://doi.org/10.1177/0305735617716756

Zeman, J., Klimes-Dougan, B., Cassano, M., \& Adrian, M. (2007). Measurement Issues in Emotion Research with Children and Adolescents. Clinical Psychology: Science and Practice, 14, 377-401. https://doi.org/10.1111/j.1468-2850.2007.00098.x

Zuo, S., Wang, S., Wang, F., \& Shi, X. (2017). The Behavioural Paths to Wellbeing: An Exploratory Study to Distinguish between Hedonic and Eudaimonic Wellbeing from an Activity Perspective. Journal of Pacific Rim Psychology, 11.

https://doi.org/10.1017/prp.2017.1 


\section{Appendices}

\section{Appendix A: "Music Club" Consent Script (Delivered at the Start of Every Session)}

You are being invited to take part in a research study looking at music and wellbeing. Before you decide whether or not to take part, it is important for you to understand what todays' session will involve.

Today we are going to complete musical activities related to the emotion of $<$ emotion focus here>. This will include listening to music displaying this emotion and completing some improvisation using the instruments. In a moment I am going to ask you to complete a questionnaire about how you are currently feeling, and I will ask you to complete this again at the end of the session. I will not be asking you to write your name on anything you complete so any information you choose to share will not be passed onto anyone else.

Are there any questions?

Is there anyone who does not want to join in with today's session?

If a child did not want to participate in the session, their parents were phoned so they could be collected. This is the schools normal procedure.

\section{Appendix B: Music Club Debrief Script (Delivered at the End of Every Session)}

Thank you for joining in with today's session. Today we have completed musical activities surrounding the emotion of <insert emotion here>. Is everybody happy for me to use your responses to both questionnaires? Remember these will be kept completely confidential as I have not asked you to complete your name on any document.

Does anyone have any questions?

Next week we will be looking at the emotion of <emotion focus here>.

Thank you and I look forward to seeing you next week.

\section{Appendix C: Control Group Consent Script for Class Teachers to Read}

As part of Miss (teacher name research project she has asked us to complete these questionnaires about how you are feeling. Is there anybody here who does not want to complete this questionnaire?

${ }^{*}$ Do not give a questionnaire to any child who does not want to do this ${ }^{*}$

Read the statement on the left and circle or shade in the smiley face to show how you feel towards each statement.

Thank you for completing the questionnaire. Do you have any questions?

If class teacher could not answer these questions from the children, they made a note of the questions so that the first author could answer them. 


\section{Appendix D: Session Plans}

\section{8 .5}

Music Sessions Weekly Plan

Exploring Emotions Through Music
Can a music programme have a positive impact on primary-age pupil's wellbeing?

A focus on a sense of belonging, self-esteem and empathy.

Acronyms: T-Teacher

TA-Assistant

IWB-Interactive whiteboard

Date: Thursday $7^{\text {th }}$ June (Session One)

Focus: Joy

Starter

\section{Learning}

Objective
Whole Class

Group Activities

Plenary
Ask the children to write down their favourite song on a piece of paper, especially one that they would like to sing. Explain that we will try to sing one of these at the start and at the end of every session.

T to explain to the children about the session (see the attached script) and check all children are happy to join in. $\mathrm{T}$ to introduce questionnaires to the children and explain how to complete them. Once questionnaires are complete discuss as a group a name for the club after school as a group.

Notes on session:
To describe the emotion of joy using music.
Explain that today we are going to be focussing on the emotion "Joy" Children discuss

What is Joy?

Can you think of a time when you felt joy? What did you do? How did

\section{it feel?}

Improvise what joy would sound like to $T$ and explain why that resembles joy.

If you were to describe the feeling of joy to music how would it sound? Write down what the children say on the flip chart paper to refer to throughout the session and in the final one.

TA to search for the songs the children TA and $\mathrm{T}$ to interact with children suggested were their favourite song and find this on either singup or youtube (TA to check the suitability before sharing with the children). listening to their improvisation and making notes on how the children are with their peers. Who works alone? Pairs? As a group?
Children can choose to work in pairs/groups or on their own.

- Improvisation: Children improvise on their chosen instrument for 2 minutes on their chosen instrument. What would joy sound like? Is this similar Children complete to some of the features we listed at questionnaires about the start of the session? their mood after the

- Perform: Ask some children to perform session and T to take an improvisation piece describing joy. any verbal feedback Remind children: Remember from the children improvisation happens in the moment about the session. TA it doesn't have to be the same as you to write down what have played before! Discuss the children say to record performance: What did they do well? feedback. Did you Why did it show the emotion joy? enjoy the session? Singing: Explain that at the end of each What could make it session we will be taking part in some better? group singing, singing each other's $\quad T$ to read script for favourite songs. Sing the song CS found debrief to the children as a group. and dismiss the children at the front office. 
Date: Thursday 14th June (Session Two)

Focus: Sadness

\begin{tabular}{|c|c|c|c|c|}
\hline Starter & $\begin{array}{l}\text { Learning } \\
\text { Objective }\end{array}$ & Whole Class & Group Activities & Plenary \\
\hline
\end{tabular}

\begin{tabular}{|c|c|c|c|c|}
\hline $\begin{array}{l}\text { Greeting to the } \\
\text { children. } \\
\mathrm{T} \text { to explain to the } \\
\text { children about the } \\
\text { session (see the } \\
\text { attached script) and } \\
\text { check all children are } \\
\text { happy to join in. } \\
\mathrm{T} \text { to give out } \\
\text { questionnaires to the } \\
\text { children and recap } \\
\text { how to complete } \\
\text { them. }\end{array}$ & $\begin{array}{l}\text { To describe the } \\
\text { emotion of } \\
\text { sadness using } \\
\text { music }\end{array}$ & $\begin{array}{l}\text { Singing. Sing one of the children's } \\
\text { favourite songs from the list given by } \\
\text { the children last week. } \\
\text { Explain that this week we are going to } \\
\text { be looking at the emotion of sadness } \\
\text { and music. Remind the children that } \\
\text { they can stop joining in if they start to } \\
\text { feel uncomfortable. } \\
\text { Put up the word Sadness on the IWB } \\
\text { (interactive whiteboard). Children } \\
\text { discuss. What is sadness? Can you } \\
\text { think of a time when you felt sad? } \\
\text { What did you do? How did it feer? } \\
\text { If you were to describe the feeling of } \\
\text { sadness to music how would it } \\
\text { sound? Write down what the children } \\
\text { say on the flip chart paper to refer to } \\
\text { throughout the session and in the final } \\
\text { one. } \\
\text { T to improvise what sadness would } \\
\text { sound like and explain why that } \\
\text { resembles sadness. }\end{array}$ & $\begin{array}{l}\text { Children can choose to work in } \\
\text { pairs/groups or on their own. } \\
\text { - Improvisation: Children improvise on } \\
\text { their chosen instrument for } 2 \text { minutes. } \\
\text { What would sadness sound like? Is } \\
\text { this similar to some of the features we } \\
\text { listed at the start of the session? } \\
\text { - Perform: Ask some children to perform } \\
\text { an improvisation piece describing } \\
\text { sadness. Remind children: Remember } \\
\text { improvisation happens in the moment it } \\
\text { doesn't have to be the same as you have } \\
\text { played before! Discuss the performance: } \\
\text { What did they do well? Why did it } \\
\text { show the emotion sadness? } \\
\text { - Singing: Group singing, singing another } \\
\text { favourite song from the children } \\
\text { choices. } \\
\text { TA and T to interact with children } \\
\text { listening to their improvisation and } \\
\text { making notes on how the children are } \\
\text { with their peers. Who works alone? Pairs? } \\
\text { As a group? Has this changed from last } \\
\text { week? }\end{array}$ & $\begin{array}{l}\text { Children complete } \\
\text { questionnaires about } \\
\text { their mood after the } \\
\text { session and T to take } \\
\text { any verbal feedback } \\
\text { from the children } \\
\text { about the session. TA } \\
\text { to write down what } \\
\text { children say to record } \\
\text { feedback. Did you } \\
\text { enjoy the session? } \\
\text { What could make it } \\
\text { better? }\end{array}$ \\
\hline
\end{tabular}

Notes on session: 
Date: Thursday 21st June (Session Three)

Focus: Anger

\begin{tabular}{|c|c|c|c|c|}
\hline Starter & $\begin{array}{l}\text { Learning } \\
\text { Objective }\end{array}$ & Whole Class & Group Activities & Plenary \\
\hline
\end{tabular}

Singing. Sing one of the children's favourite songs from the list given by the children last week.

Explain that this week we are going to be looking at the emotion of anger and music. Remind the children that they

Greeting to the

children.

$\mathrm{T}$ to explain to the children about the session (see the attached script) and check all children are happy to join in.

$\mathrm{T}$ to give out questionnaires to the children and recap how to complete them.

Notes on session: uncomfortable. Put up the word anger on the IWB. Children discuss.

To describe the Anger-What is anger? Can you think of a time when you felt angry? anger using did you do? How did it feel? Children contribute their discussions to the whole group

Q) If you were to describe the it sound?

Write down what the children say on the flip chart paper to refer to throughout the session and in the final one.

Improvise what anger would sound like using the children's suggestions.
Children can choose to work in pairs/groups or on their own.

- Improvisation: Children improvise on feeling of anger to music how would improvisation happens in the moment $i$
As a group? Has this changed from previous weeks? their chosen instrument for 2 minutes.

What would anger sound like? Is this similar to some of the features we listed at the start of the session?

- Perform: Ask some children to perform an improvisation piece describing anger. Remind children: Remember doesn't have to be the same as you have played before! Discuss the performance: What did they do well? Why did it show the emotion anger?

Singing: Group singing, singing another favourite song from the children choices.

TA and $\mathrm{T}$ to interact with children listening to their improvisation and making notes on how the children are with their peers. Who works alone? Pairs? Children complete questionnaires about their mood after the session and $\mathrm{T}$ to take any verbal feedback from the children about the session. TA to write down what children say to record feedback. Did you enjoy the session? What could make it better?

T to read script for debrief to the children and dismiss the children at the front office. 
Date: Thursday 28th June (Session Four)

Focus: Disgust

\begin{tabular}{lll}
\hline Starter & $\begin{array}{l}\text { Learning } \\
\text { Objective }\end{array}$ & Whole Class Plenary \\
\hline
\end{tabular}

Singing. Sing one of the children's Children can choose to work in

favourite songs from the list given by pairs/groups or on their own.

the children last week. $\quad$ Improvisation: Children improvise on

Explain that this week we are going to their chosen instrument for 2 minutes. Children complete

be looking at the emotion of disgust What would disgust sound like? Is questionnaires about and music. Remind the children that this similar to some of the features we their mood after the

Greeting to the

children.

T to explain to the children about the session (see the attached script) and check all children ar happy to join in. $\mathrm{T}$ to give out questionnaires to the children and recap how to complete them.

Notes on session:
To describe the emotion of disgust using music.

(a)
they can stop joining in if they start to feel uncomfortable.

Put up the word disgust on the IWB Children discuss:

What is disgust? Can you think of a time when you felt disgust? What did you do? How did it feel? If you were to describe the feeling of disgust to music how would it sound?

Write down what the children say on the flip chart paper to refer to throughout the session and in the final one. Both $T$ and TA (if confident enough) to Improvise what disgust would sound like using the children's suggestions.
TA and T to interact with children listening to their improvisation and

\section{listed at the start of the session? session and $\mathrm{T}$ to take}

- Perform: Ask some children to perform any verbal feedback an improvisation piece describing from the children disgust. Remind children: Remember about the session. TA improvisation happens in the moment it to write down what doesn't have to be the same as you have children say to record played before! Discuss the performance: feedback. Did you

What did they do well? Why did it enjoy the session? show the emotion disgust? What could make it

- Singing: Group singing, singing another better? favourite song from the children choices.

$\mathrm{T}$ to read script for debrief to the children and dismiss the children at the front making notes on how the children are office. with their peers. Who works alone? Pairs? As a group? Has this changed from previous weeks? 
Date: Thursday 5th July (Session Five)

Focus: Fear

\begin{tabular}{|c|c|c|c|c|}
\hline Starter & $\begin{array}{l}\text { Learning } \\
\text { Objective }\end{array}$ & Whole Class & Group Activities & Plenary \\
\hline
\end{tabular}

Singing. Sing one of the children's favourite songs from the list given by the children last week.

Explain that this week we are going to be looking at the emotion of fear and music. Remind the children that they

Greeting to the children.

$\mathrm{T}$ to explain to the children about the session (see the attached script) and To describe the check all children are emotion of fear happy to join in. using music.

$\mathrm{T}$ to give out questionnaires to the children and recap how to complete them.

Notes on session: can stop joining in if they start to feel uncomfortable.

Put up the word fear on the IWB.

Children discuss. Write down what the children say on the flip chart paper to refer to one.
- Children can choose to work in pairs/groups or on their own.

- Improvisation: Children improvise on their chosen instrument for 2 minutes. What would fear sound like? Is this similar to some of the features we listed at the start of the session?

- Perform: Ask some children to perform an improvisation piece describing fear. Remind children: Remember improvisation happens in the moment it

Fear-What is fear? Can you think ot doesn't have to be the same as you have a time when you felt fear? What did played before! Discuss the performance: you do? How did it feel? What did they do well? Why did it If you were to describe the feeling of show the emotion disgust? fear to music how would it sound? - Singing: Group singing, singing another favourite song from the children choices.

throughout the session and in the final TA and $\mathrm{T}$ to interact with children

listening to their improvisation and making notes on how the children are

Both T and TA to improvise what fear with their peers. Who works alone? Pairs?

Children complete questionnaires about their mood after the session and $\mathrm{T}$ to take any verbal feedback from the children about the session. TA to write down what children say to record feedback. Did you enjoy the session? What could make it better?

$\mathrm{T}$ to read script for debrief to the children and dismiss the children at the front office. would sound like using the children's As a group? Has this changed from suggestions. 
Date: Thursday 12th July (Session Six)

Focus: Emotion Storyboard

\begin{tabular}{lll}
\hline Starter & $\begin{array}{l}\text { Learning } \\
\text { Objective }\end{array}$ & Whole Class Plenary Activities \\
\hline
\end{tabular}

Children design their story board of emotions. They can choose to complete this activity in pairs, on their own or within a group. Example: A person feels happy (joyful music) then he sees a snake which he is scared of (fear music) snake slithers away, doesn't like the way it looks (disgust music) snake has gone (joyful music).

Greeting to the children.

$\mathrm{T}$ to explain to the children about the session (see the attached script) and check all children are happy to join in. $\mathrm{T}$ to give out questionnaires to the children and recap how to complete them.

Notes on session:
Singing. Sing one of the children's favourite songs from the list given by the children last week.

Explain that this week we are going to be pulling together all of our ideas we have created with emotions and music over the past five weeks. Remind the children that they can stop joining in if they start to feel uncomfortable. Ask the children for the different To create a piece emotions we have used over the weeks of music and the way we have used music to describing a set describe-record these on the IWB. of emotions. Explain that we are going to use the ideas we have created over the past few weeks to create a story using music. Show the story board template.

MODEL: Explain that $\mathrm{T}$ and TA have worked together to create a story and some music to go with this. Share the storyboard (see example in group activities) and play the music to go with this.

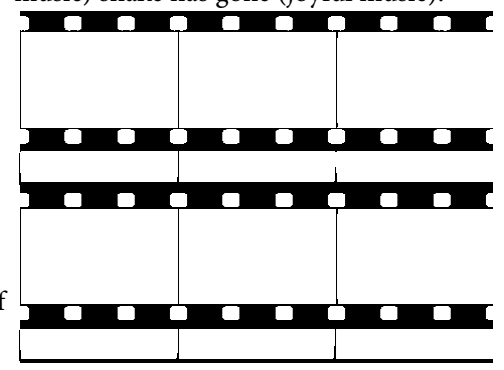

Story Board Template-children draw pictures and write notes about music in the blue space. This will be cut into strips so children can choose to complete one, two three + emotions.

Compose: Children create their ideas through music and practice this, adding to you did not enjoy? their story boards to help them remember what they have used.

Perform: Children perform their emotion pieces in the celebration assembly on the Friday if they choose to.
$\mathrm{T}$ to read script for debrief to the children and dismiss the children at the front office.

Children complete questionnaires about their mood after the any verbal feedback from the children about the sessions. TA to write down what children say to record feedback. Did you enjoy the sessions? Is there anything you enjoyed? Anything

(1) session and $\mathrm{T}$ to take

Singing: Have a vote as a group from the list of the favourite songs they have been singing over the past six weeks and sing this one (this can also be performed in the assembly if they choose to do this). $\mathrm{TA}$ and $\mathrm{T}$ to interact with children listening to their discussions and making notes on how the children are with their peers. Who works alone? Pairs? As a group? Has this changed from previous weeks? 


\section{Appendix E: Child Wellbeing Questionnaire (CWB)}

Please note the abbreviations beside the questions in Appendices $\mathrm{E}$ and $\mathrm{F}$ have been added to enable replication and were not on the questionnaire that the children received. ( $\mathrm{SE}=$ Self-esteem, $\mathrm{B}=$ Belonging, $\mathrm{E}=$ Empathy).

Number:

Date:

Here are some statements or descriptions about how you might have been feeling or thinking about things recently.

For each tick the box which best describes your thoughts and feelings; there are no right or wrong answers.

\begin{tabular}{|c|c|c|c|c|}
\hline Never & $\begin{array}{l}\text { Not much } \\
\text { of the time }\end{array}$ & $\begin{array}{l}\text { Some of } \\
\text { the time }\end{array}$ & $\begin{array}{l}\text { Quite a lot } \\
\text { of the time }\end{array}$ & $\begin{array}{c}\text { All of the } \\
\text { time }\end{array}$ \\
\hline
\end{tabular}

1. I am happy (SE).

2. I prefer to work alone that with other children (B).

3. When I am angry or upset at someone, I try to imagine what he or she is thinking or feeling (E).

4. I often wish I was someone else (SE).

5. I have lots of friends (B).

6. I can tell by looking at a person whether they are happy (E).

7. I think there are a lot of things about myself I would change if I could (SE).

8. I get upset when I see a child being hurt (E).

9. I feel like I am a part of my school (B).

10. I believe I am a failure (SE).

11. It makes me sad to see a child who can't find anyone to play with (E).

12. There are lots of people I like to spend time with (B).

13. I am happy with who I am (SE).

14. I don't feel included in my friendship group (B).

Any other comments:

Thank you for completing this questionnaire 


\section{Appendix F: Parent Questionnaire (PQ)}

Here are some statements or descriptions about thoughts and feelings.

Please tick the box which you think best describes your child; there are no right or wrong answers.

Never $\begin{aligned} & \text { Not much } \\ & \text { of the time }\end{aligned} \begin{aligned} & \text { Some of Quite a lot All of } \\ & \text { the time of the time the time }\end{aligned}$

1. My child is happy (SE).

2. My child prefers to work alone rather than with other children (E).

3. When my child is angry or upset at someone, they consider what he or she is thinking or feeling (B).

4. My child says they wish they were someone else (SE).

5. My child has lots of friends (E).

6. My child can tell whether someone is happy by looking at a person (B).

7. My child seems comfortable with themselves (SE).

8. My child can get upset when he/she sees a child being hurt (E).

9. My child feels a part of their school (B).

10. My child believes they are successful (SE).

11. My child is sad to see a child who can't find anyone to play with (E)

12. There are lots of people my child likes to spend time with (B).

13. My child is happy with who they are (SE).

14. My child doesn't feel included in their friendship group (B).

Any other comments:

Thank you for completing this questionnaire 


\section{Appendix G: List of Songs Used to Elicit Emotional Responses} (First Minute Played)

\begin{tabular}{|c|c|c|c|c|}
\hline Emotion & Song & Composer & Recording & Year \\
\hline Joy & Tico Tico & Zequinha de Abreu & $\begin{array}{l}\text { Performed by Berlin } \\
\text { Philharmonic. Conducted } \\
\text { by Daniel Barenboim }\end{array}$ & $1917 / 2001$ \\
\hline Sadness & Nuvole Bianche & Ludovico Einaudi & Album: Una Mattina & 2004 \\
\hline Anger & Mars, The Planets & Gustav Holst & $\begin{array}{l}\text { Performed by The Royal } \\
\text { Liverpool Philharmonic } \\
\text { Orchestra. Conducted by Sir } \\
\text { Charles Mackerras }\end{array}$ & $1916 / 2010$ \\
\hline Disgust & $\begin{array}{c}\text { Piano } \\
\text { Concerto, Op24 }\end{array}$ & Arnold Schoenberg & $\begin{array}{c}\text { Performed by The } \\
\text { Cleveland Orchestra. } \\
\text { Conducted by Pierre Boulez }\end{array}$ & $1942 / 2000$ \\
\hline Fear & $\begin{array}{l}\text { Dark Piano for } \\
\text { Dark Thoughts }\end{array}$ & Lukas King & Lukas King & 2017 \\
\hline
\end{tabular}

\section{Appendix H: Recorded Audio Examples of Children's Music Compositions}

Recording Track 1: Example of Fear Music,

Recording Track 2: Example of Fear Music,

Recording Track 3: Example of Storyboard piece: Sadness,

Recording Track 4: Example of Storyboard piece: Emotions.

\section{Supplementary Table}

Supplementary Table S1. Intervention group children and parent/caregiver self-report scores over time.

\begin{tabular}{lccccc}
\hline & N & Minimum & Maximum & Mean & SD \\
\hline Children Self-report & & & & & \\
Self-esteem Week 1 & 15 & 2.20 & 4.60 & 3.60 & .68 \\
Self-esteem Week 2 & 16 & 2.40 & 5.00 & 3.99 & .82 \\
Self-esteem Week 3 & 15 & 1.40 & 5.00 & 3.55 & 1.25 \\
Self-esteem Week 4 & 7 & 2.60 & 5.00 & 4.09 & .85 \\
Self-esteem Week 5 & 15 & 1.20 & 5.00 & 3.64 & 1.21 \\
Self-esteem Week 6 & 17 & 1.80 & 5.00 & 3.80 & 1.06 \\
Empathy Week 1 & 13 & 2.25 & 4.75 & 3.50 & .70 \\
Empathy Week 2 & 16 & 1.50 & 5.00 & 3.66 & 1.01 \\
Empathy Week 3 & 15 & 1.50 & 5.00 & 3.40 & 1.04 \\
Empathy Week 4 & 7 & 2.25 & 5.00 & 3.71 & 1.02 \\
Empathy Week 5 & 15 & 1.75 & 5.00 & 3.68 & .90 \\
Empathy Week 6 & 17 & 1.50 & 4.75 & 3.69 & .89 \\
Belonging Week 1 & 15 & 2.60 & 5.00 & 3.74 & .69
\end{tabular}




\section{Continued}

\begin{tabular}{cccccc}
\hline Belonging Week 3 & 16 & 1.60 & 5.00 & 3.71 & .79 \\
Belonging Week 4 & 7 & 3.20 & 4.60 & 3.91 & .50 \\
Belonging Week 5 & 15 & 1.80 & 4.80 & 3.52 & .83 \\
Belonging Week 6 & 17 & 1.40 & 5.00 & 3.64 & .95 \\
Parent/Caregiver Self-report & & & & & \\
Self-esteem Week 1 & 8 & 3.00 & 4.80 & 4.15 & .54 \\
Self-esteem Week 6 & 4 & 3.20 & 4.40 & 4.00 & .54 \\
Empathy Week 1 & 8 & 2.50 & 5.00 & 3.66 & .87 \\
Empathy Week 6 & 4 & 2.75 & 4.50 & 3.69 & .75 \\
Belonging Week 1 & 8 & 3.20 & 4.80 & 3.75 & .52 \\
Belonging Week 6 & 4 & 3.40 & 4.80 & 4.00 & .59 \\
\hline
\end{tabular}

